\title{
OTR8 - METABOLÔMICA APLICADA NA IDENTIFICAÇÃO DE POTENCIAIS ALVOS DE INTERVENÇÃO TERAPÊUTICA NAS DOENÇAS MICOBACTERIANAS
}

$\underline{\text { Katherine Antunes de Mattos }}{ }^{1,2}$, Viviane Carneiro Gonçalves Oliveira ${ }^{1}$, Luiz Caetano Martha Antunes ${ }^{3}$, Euzenir Nunes Sarno ${ }^{4}$, Patricia Torres Bozza ${ }^{6}$, Georgia Correa Atella $^{7}$ e Maria Cristina Vidal Pessolani ${ }^{1}$.

${ }^{1}$ Laboratório de Microbiologia Celular, Instituto Oswaldo Cruz, Fundação Oswaldo Cruz, Rio de Janeiro

${ }^{2}$ Laboratório de Controle de Qualidade, Instituto de Tecnologia em ImunobiológicosBioManguinhos, Fundação Oswaldo Cruz, Rio de Janeiro

${ }^{3}$ Michael Smith Laboratories, The University of British Columbia, Vancouver, Canada;

${ }^{4}$ Laboratório de Hanseníase, Instituto Oswaldo Cruz, Fundação Oswaldo Cruz, Rio de Janeiro

${ }^{5}$ Laboratório de Imunofarmacologia, Instituto Oswaldo Cruz, Fundação Oswaldo Cruz, Rio de Janeiro

${ }^{6}$ Laboratório de Bioquímica de Lipídeos e Lipoproteínas, Instituto de Bioquímica Médica, Universidade Federal do Rio de Janeiro

Objetivos: Mapear o perfil metabólico modulado pela infecção micobacteriana, usando a abordagem metabolômica. Esta estratégia metodológica visa o entendimento contemporâneo da integração metabólica entre patógeno-hospedeiro, possibilitando a utilização desta ferramenta investigativa para identificar potenciais alvos para estratégias terapêuticas no tratamento de doenças metabolóbico-infecciosas, como hanseníase e tuberculose.

Metodologia: O perfil metabólico disparado durante a infecção foi analisado por DIFTICR-MS. O perfil lipídico das células de pacientes e infectadas in vitro foi traçado por análises de HPTLC, DI-FTICR-MS e citometria de fluxo. A expressão dos níveis de enzimas e receptores envolvidos na homeostase do colesterol foi investigada por RT-PCR e/ou Western Blot. Estudos funcionais de enzimas da síntese de novo de colesterol foram realizados utilizando a abordagem de incorporação de acetato e análise por cintilografia e a funcionalidade dos receptores de colesterol exógeno foi monitorada por microscopia 
confocal utilizando LDL-colesterol fluorescente. Microscopia em tempo real e confocal de células isoladas de pacientes e infectadas in vitro foram utilizadas para identificar os locais de acúmulo de colesterol no interior das células infectadas. A importância do colesterol na viabilidade micobacteriana foi investigada utilizando drogas que interferem nesta via, como estatinas, sendo a viabilidade determinada pelo LIVE/DEAD Bactlight Bacterial viability Kit por citometria de fluxo.

Resultados: A abordagem metabolômica nos permitiu identificar várias vias metabólicas alteradas durante a infecção micobacteriana, destacando-se as vias do metabolismo lipídico. A análise lipidômica desta interação identificou a via do colesterol como predominantemente modulada durante a infecção. As implicações funcionais preditas pela avaliação gênica e protéica de enzimas e receptores envolvidos na homeostase do colesterol demonstram a capacidade da micobactéria em induzir a síntese de novo e incorporação de colesterol, estando estes localizados no fagosoma contendo bactérias. Embora não se tenha a completa apreciação das fontes de carbono utilizadas pelas micobactérias durante a infecção, existem evidências genéticas que a micobactéria pode utilizar o colesterol como fonte nutricional. Assim, utilizamos a estratégia de inibir a via de síntese e captação do colesterol pela intervenção terapêutica com lovastatina, resultando em uma ação bactericida, nos modelos de infecção para micobactérias, hanseníase e tuberculose.

Conclusão: $O$ mapeamento metabólico nos permitiu identificar uma importante via metabólica modulada durante a infecção micobacteriana, a via do colesterol. O conhecimento deste perfil metabólico nos permitiu propor uma estratégia racional de utilização de drogas baseado na enzima chave da via de síntese do colesterol, a 3-hidroxi3-metilglutaril-coenzima A redutase (HMGCR). Assim, a abordagem metabolômica tornar-se um método importante para determinar a condição metabólica de uma doença, podendo mapear biomarcadores que sirvam de impressão digital da infecção, auxiliando no desenvolvimento de kits diagnósticos mais específicos além de contribuir nas estratégias de desenvolvimento racional de medicamentos baseado em alvos identificados como cruciais para a patofisiológica das infecções bacterianas. 